\title{
Modeling the Human Kinetic Adjustment Factor for Inhaled Volatile Organic Chemicals: Whole Population Approach versus Distinct Subpopulation Approach
}

\author{
M. Valcke, ${ }^{1,2}$ A. Nong, ${ }^{1}$ and K. Krishnan ${ }^{1}$ \\ ${ }^{1}$ Département de Santé Environnementale et de Santé au Travail, Université de Montréal, Montreal, QC, Canada H3T $1 A 8$ \\ ${ }^{2}$ Institut National de Santé Publique du Québec, Montréal, QC, Canada H2P 1E2
}

Correspondence should be addressed to K. Krishnan, kannan.krishnan@umontreal.ca

Received 21 September 2011; Accepted 21 October 2011

Academic Editor: Marina V. Evans

Copyright ( $) 2012$ M. Valcke et al. This is an open access article distributed under the Creative Commons Attribution License, which permits unrestricted use, distribution, and reproduction in any medium, provided the original work is properly cited.

\begin{abstract}
The objective of this study was to evaluate the impact of whole- and sub-population-related variabilities on the determination of the human kinetic adjustment factor (HKAF) used in risk assessment of inhaled volatile organic chemicals (VOCs). Monte Carlo simulations were applied to a steady-state algorithm to generate population distributions for blood concentrations (CAss) and rates of metabolism (RAMs) for inhalation exposures to benzene (BZ) and 1,4-dioxane (1,4-D). The simulated population consisted of various proportions of adults, elderly, children, neonates and pregnant women as per the Canadian demography. Subgroupspecific input parameters were obtained from the literature and P3M software. Under the "whole population" approach, the HKAF was computed as the ratio of the entire population's upper percentile value (99th, 95th) of dose metrics to the median value in either the entire population or the adult population. Under the "distinct subpopulation" approach, the upper percentile values in each subpopulation were considered, and the greatest resulting HKAF was retained. CAss-based HKAFs that considered the Canadian demography varied between 1.2 (BZ) and 2.8 (1,4-D). The "distinct subpopulation" CAss-based HKAF varied between 1.6 (BZ) and 8.5 (1,4-D). RAM-based HKAFs always remained below 1.6. Overall, this study evaluated for the first time the impact of underlying assumptions with respect to the interindividual variability considered (whole population or each subpopulation taken separately) when determining the HKAF.
\end{abstract}

\section{Introduction}

An interindividual variability (or uncertainty) factor (IVF) of a default value of 10 is usually applied to the point of departure (POD) for deriving reference doses (RfDs) or reference concentrations (RfCs) for use in noncancer risk assessment [1-3]. As reviewed by Price et al. [4], the IVF has historically been defined as a factor required to protect the sensitive members of the population since the POD is generally determined for average healthy individuals. Actually, two models have been proposed to describe the IVF. Under the "sensitive population" model, the IVF is applied to correct for the possible failure of a critical study to include a sufficient number of members pertaining to distinct subpopulation exhibiting an increased sensitivity. Conversely, under the "finite sample size" model, the application of the IVF relates to the possibility that the retained POD may fail to identify the toxicity threshold in the overall population simply because of the finite size of the sample in which it was determined [4]. Thus, the IVF accounts for the overall biological variability in the human population.

In the last 20 years, the IVF has been divided into two constitutive components (toxicokinetic and toxicodynamic factors), equal to 3.16 each based on pharmaceutical data [5-7]. This subdivision can be used in the evaluation of the magnitude and adequacy of the IVF for specific chemicals, and its replacement when appropriate data are available, by quantifying chemical-specific adjustment factors (CSAFs) $[8,9]$. Under this method, the CSAF for interindividual variability in toxicokinetics, also referred to as the human kinetic adjustment factor (HKAF), can be determined based on the population distributions of relevant pharmacokinetic parameters (e.g., half-life, maximal concentration). The HKAF is calculated as the ratio between the upper percentile 
TABle 1: Chemical-specific parameters used in the steady-state algorithm.

\begin{tabular}{|c|c|c|}
\hline \multirow{2}{*}{ Parameter } & \multicolumn{2}{|c|}{ Chemical } \\
\hline & Benzene $^{(a)}$ & 1,4-Dioxane $\mathrm{e}^{(\mathrm{b})}$ \\
\hline$V \max _{\mathrm{c}}\left(\mathrm{mg} / \mathrm{h}-\mathrm{kg}^{0.75}\right)$ & 2.11 & 0.27 \\
\hline $\mathrm{Km}(\mathrm{mg} / \mathrm{L})$ & 0.1 & 3.0 \\
\hline $\begin{array}{l}\text { Blood: air partition } \\
\text { coefficient }\left(P_{b}\right)\end{array}$ & 7.4 & 3650 \\
\hline $\begin{array}{l}\text { Exposure concentration } \\
\left(\mathrm{mg} / \mathrm{m}^{3}, \mathrm{UF} \times \mathrm{RfC}\right)^{(\mathrm{c})}\end{array}$ & 0.3 & 3 \\
\hline
\end{tabular}

value of a parameter (i.e., 95th) and its central tendency value (i.e., median) in the whole population or between an upper percentile value in a presumed susceptible subpopulation and the central tendency value in the general healthy population $[8,9]$.

Neither the historical definitions of IVF [4] nor the IPCS guidance document on CSAFs [8] clearly defines the "average healthy individual," forming the point of comparison for the presumed sensitive subpopulations. Particularly, it is unclear as to whether this individual is the average healthy adult or the average healthy individual from the whole population (which includes both healthy adults and sensitive subpopulations). But presumably because the POD used to derive the $\mathrm{RfD}$ or $\mathrm{RfC}$ is generally determined in healthy adults (animal or human) [10], HKAF evaluations conducted using experimental data for drugs [11-13] or PBPK model simulation data for environmental toxicants [14-16] have relied on what can be called a "distinct subpopulation" approach. Thus, the experimental or simulated data in the presumed susceptible individuals (e.g., neonates, pregnant women, elderly, polymorphic individuals) have often been compared with the corresponding data in healthy adults.

Alternatively, HKAF can be quantified using a "whole population" approach as done recently by Mörk and Johanson [17]. In this study, HKAFs were calculated for inhaled acetone based on a simulated distribution of steady-state blood concentration in an entire population, including adults and various age-defined groups of children. The PBPK modeling results in the different subgroups were weighted according to demographic representation in Sweden. Excluding the endogenous production of acetone, an HKAF of 1.9 was obtained by dividing the 95th percentile value of the entire population by the median. In comparison, using the 95th percentile value of that same dose metric in 3-monthold babies as well as 10 and $15 \mathrm{yr}$ old children resulted in HKAFs of 2, 2.4, and 1.7, respectively.

The hypothesis that the HKAF determined upon the "whole population" approach is quite different from the one determined based on the "distinct subpopulation" approach stems from the results of Mörk and Johanson [17]. This potential difference could be significant from a regulatory standpoint because it may not lead to comparable levels of protection for the different subgroups that compose the whole population. It is also not known whether the population composition and the chemical considered may impact this potential difference. Thus, the objective of the current study was to evaluate the magnitude and adequacy of the HKAFs determined by the "whole population" approach as compared to the "distinct subpopulation" approach. In effect, population distributions of internal dose metrics following chronic exposure to two chemicals exhibiting different clearance characteristics were used to compute the HKAF as

(i) the ratio of the upper percentile value in the entire population including adults and nonadults over the median in adults and in this entire population;

(ii) the ratio of the upper percentile value in presumed susceptible subpopulation over the median in adults and in the entire population including adults and non-adults.

\section{Methods}

A physiologically based steady-state algorithm combined with Monte Carlo simulation software was used to generate population distributions of blood concentration (CAss) and rate of metabolism (RAM) for chronic inhalation exposure to two chemicals with contrasting systemic clearance characteristics. The population distributions were reconstructed based on different proportions of randomly selected adults, elderly, children, neonates, and PW, and they were used to compute HKAFs based on "whole population" and "distinct subpopulation" approaches.

\subsection{Selection of Surrogate Chemicals and Their Specific} Parameters. Two VOCs were chosen as surrogate chemicals because they exhibit contrasting systemic clearances based on their pulmonary clearance potential (different blood : air partition coefficient $\left(P_{b}\right)$ ) and their hepatic clearance (different hepatic extraction ratios). Benzene was chosen as an extensively cleared chemical because of its high pulmonary clearance (low $P_{b}, 7.4$ ) and high hepatic extraction ratio. Conversely, 1,4-dioxane was chosen as a poorly cleared chemical due to its low pulmonary clearance $\left(P_{b}=3650\right)$ and low hepatic extraction ratio. While benzene is a known substrate of CYP2E1 [18], for which extensive data on interindividual variability are available [19, 20], 1,4-dioxane was included in this study to facilitate the coverage of a range of physico/biochemical properties of potential substrates of CYP2E1 [21]. Chemical-specific parameters are indicated in Table 1 and were taken from the literature $[10,22,23]$. The choice of these two surrogate VOCs and associated kinetic parameters was undertaken to reflect the range of kinetic characteristics of hypothetical substances for evaluating the HKAF. As such, the present modeling study did not focus on any aspect of the risk assessment relating to these specific chemicals.

2.2. Use of a Biologically Based Steady-State Model for the Simulation of Continuous Inhalation Exposure in Different Subpopulations. The current study relies on the use of 
a steady-state model for inhalation exposures (e.g., [2427]), because the current study aimed at reconstructing population distributions of internal dose metrics for continuous lifetime exposures. Briefly, the algorithm computes the arterial blood concentration at steady-state (CAss) from the alveolar ventilation rate $(\mathrm{Qp})$, the concentration in air $(\mathrm{Ci})$, and the hepatic $\left(\mathrm{Ql} \times E_{\text {hep }}\right)$ and pulmonary $\left(\mathrm{Qp} / P_{b}\right)$ clearances [27]:

$$
\text { CAss }=\frac{\mathrm{Qp} \times \mathrm{Ci}}{\mathrm{Ql} \times E_{\mathrm{hep}}+\mathrm{Qp} / P_{b}},
$$

where $\mathrm{Ql}$ is the liver blood flow, $P_{b}$ is the blood: air partition coefficient, and $E_{\text {hep }}$ is the hepatic extraction ratio of the chemical and is calculated from its intrinsic clearance (Clint) as follows:

$$
E_{\text {hep }}=\frac{\text { Clint }}{\text { Clint }+ \text { Ql }} \text {. }
$$

Also, the rate of metabolised parent compound per unit volume of liver (RAM) is calculated as

$$
\mathrm{RAM}=\frac{\mathrm{CA}_{\mathrm{ss}} \times \mathrm{Ql} \times E_{\text {hep }}}{\mathrm{Vl}} .
$$

As indicated in Table 2, Qp, Ql, and $\mathrm{Vl}$ were calculated for a given individual by applying equations derived from Price et al. [28] to the individual's body weight [16]. The input data are listed in Table 2 for each subpopulation considered [15, $16,19,20,28,29]$. These include six age groups covering the lifespan (neonates $(0-30 \mathrm{~d})$, infants ( $1-12 \mathrm{mo})$, toddlers (1$3 \mathrm{yr})$, children/adolescents (4-17 yr), adults (18-64 yr), and elderly (65-90 yr)), as well as pregnant women (15-44 yr). Ql and $\mathrm{Vl}$ for pregnant women were actually calculated on the basis of the body weight for nonpregnant women, whereas the appropriate increase in alveolar ventilation rate at any time during pregnancy was accounted for when computing Qp [16].

\subsection{Generation of Distributions of Internal Dose Metrics} by Means of Monte Carlo Simulations. Constant inhalation exposure to a benzene concentration corresponding to $10 \times$ the RfC (Table 1) was simulated in each subpopulation. Given the lack of an RfC for 1,4-dioxane, and its approximately tenfold greater RfD compared to benzene [10], a concentration that was ten times greater than the benzene concentration was specified. Monte Carlo simulations were performed using the Crystal Ball software (Oracle, Redwood Shores, CA) to generate distributions of the various internal dose metrics (see below). The intrinsic clearance in (2) was corrected for a given individual in any subpopulation by adjusting the maximum rate of metabolism ( $\left.V \max _{\text {ind }}\right)$ using enzyme-specific catalytic turnover [14-16]. This was determined based on the $V \max$ in an adult of average body weight (BW avg_ad $_{1}$ ), as well as the (individual (ind)/average adult (avg_ad)) ratios of the liver volumes and CYP2E1 hepatic content (in pmol/mg of microsomal protein):

$$
\begin{aligned}
& V \max _{\text {ind }} \\
& \quad=\frac{V_{\text {max }_{\mathrm{c}}} \times \mathrm{BW}_{\text {avg_ad }} 0.75}{[\mathrm{CYP} 2 \mathrm{E} 1]_{\text {avg_ad }} \times \mathrm{Vl}_{\text {avg_ad }}} \times[\mathrm{CYP} 2 \mathrm{E} 1]_{\text {ind }} \times \mathrm{Vl}_{\text {ind }} .
\end{aligned}
$$

A constant hepatic microsomal protein concentration was assumed across the subpopulations as discussed in Valcke and Krishnan [16].

2.3.1. Distributions in the "Whole Population" and Corresponding HKAFs. Distributions of the internal dose metrics were generated for a theoretical population of 100,000 people with the demographic characteristics of Canada [30]. Therefore, the number of iterations used in the Monte Carlo simulations for each subpopulation corresponded to the targeted number of individuals. This number was based on the demographic proportions of each subpopulation (Table 3). Because the number of individuals appeared relatively constant across census' age ranges of same duration, the number of individuals pertaining to an age range different than those defined in the census could easily be estimated. For example, the number of toddlers aged 1-3 was considered as $60 \%$ of the total individuals $0-4 \mathrm{yr}$ old. Finally, the number of pregnant women was calculated based on the pregnancy rate of 104/1,000 from Ventura et al. [31] and on the number of women aged 15-44 yr from the census data. The dose metric values "generated" by the Monte Carlo simulations for each subpopulation were then merged into a single "Canadian population dataset" of 100,000 values. To calculate the HKAFs based on the "whole population" approach, the ratio of the upper percentile value of the dose metric in the entire Canadian population to its median value was computed. The percentage of each subpopulation that was protected by a "whole population" HKAF was determined by identifying the number of individuals in each subpopulation exhibiting an internal dose metric that was lower than the entire population's upper percentile value underlying the HKAF, that is, 95th or 99th.

\subsubsection{Distributions in Each "Distinct Subpopulation" and} Corresponding HKAFs. Distributions of the internal dose metrics for 100,000 individuals of each subpopulation were generated and the chemical- and dose-metric-specific HKAFs were calculated based on the "distinct subpopulation" approach, that is, as the ratio of the upper percentile value (i.e., 95th or 99th) in each subpopulation to the median value in adults or the whole Canadian population (see above). Also, for a given dose metric, the greatest "distinct subpopulation-" based HKAF was multiplied by the median in the whole Canadian population (see above) to obtain a threshold dose metric value. This threshold corresponded to the percentile that was referred to for determining the proportion of individuals from the entire population that was covered by the greatest "distinct subpopulation" HKAF. 


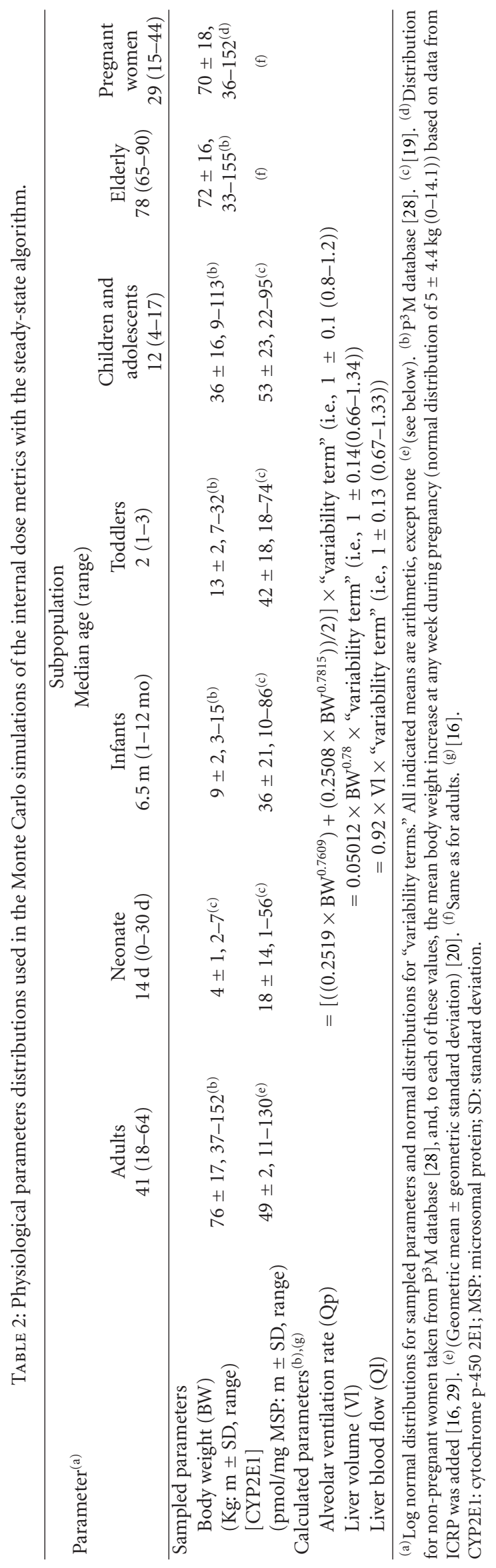


TABLE 3: Reconstruction of the hypothetical populations of 100,000 people with the Canadian demographic profile.

\begin{tabular}{lcc}
\hline Subpopulation (age range) & $\begin{array}{c}\text { Canadian population in 2009(a) } \\
\text { Median age }=39.7 \text { yr } \\
\text { Corresponding reconstructed population size and } \\
\text { number }(n) \text { of Monte Carlo iterations }\end{array}$ \\
\hline Adults (18-64) & $\begin{array}{c}\text { Population size (\%) } \\
\text { Neonates (0-30 d) }\end{array}$ & 93,923 \\
Infants (1-12 mo) & $21,685,253(63.92)$ & 1,015 \\
Toddlers (1-3) & $31,303(0.09)$ & 3,322 \\
Children and adolescents & $1,126,896(3.32)$ & 15,866 \\
(4-17) & $5,382,420(15.87)$ & 13,662 \\
Elderly (65-90) & $4,634,673(13.66)$ & 2,119 \\
Pregnant women ${ }^{(b)}(15-44)$ & $718,950(2.12)$ & 100,000 \\
\hline TOTAL & $33,923,824(100)$ &
\end{tabular}

2.4. Evaluation of the Impact of Demography on the Computed HKAFs. Given that the HKAF values as computed herein rely on the distribution of internal dose metrics in a general population composed of various proportions of each subpopulation, it was hypothesized that the demographic characteristics of a given general population may impact this calculation. To test this hypothesis, HKAFs were evaluated on the basis of dose metric distributions generated for a theoretical "younger population." These distributions were reconstructed by multiplying by 3 the number of individuals of each subpopulation $<18 \mathrm{yr}$, as well as pregnant women, as compared to the numbers that were previously used to reconstruct the Canadian population distributions (Table 3). The number of adults was also adjusted to maintain a total of 100,000 dose metric values. Thus, more than $60 \%$ of the resulting "younger population" was aged $<18 \mathrm{y}$, as compared to approximately $20 \%$ for the Canadian population.

\section{Results}

3.1. Distributions of Internal Dose Metrics in Each Subpopulation and the Entire Canadian Population. Figures 1 and 2 show the simulation of internal dose metric distributions in each subpopulation (making up the entire Canadian population) exposed to benzene and 1,4-dioxane, respectively. The shapes of the Canadian population distributions appeared normal for CAss of benzene and lognormal in the other cases. The ranges (1st-99th percentile) and median dose metrics that were obtained when simulating 100,000 individuals in each subpopulation are indicated in Table 4. Based on the median and 99th percentile dose metrics, neonates and pregnant women were the most susceptible subpopulations (i.e., they exhibited the highest dose metric) based on CAss and RAM, respectively. The median dose metric in the most susceptible subpopulation was always greater than the median dose metric in the Canadian population, but it was lower than the 99th percentile value, except for the CAss value for 1,4-dioxane. In this case, the median value in neonates $(2.3 \mathrm{mg} / \mathrm{L})$ was greater than the 99 th percentile value in the whole population $(2.14 \mathrm{mg} / \mathrm{L})$. The internal variability of internal dose metrics in the Canadian population can be appraised by the ratio of the 99th to the 1 st percentile values. The greatest variability was obtained for 1,4-dioxane based on simulations of CAss exhibiting an approximately sevenfold difference. The population variability was lower in every other case ((99th/1st percentile) ratios lower than 3). Similar trends were obtained for each specific subpopulation, although the magnitude of the differences varied. In particular, neonates exhibited a tenfold (99th/1st percentile) ratio of CAss for 1,4-dioxane. This dose metric exhibits a variability leading to such ratio that is always greater than 5 regardless of the subpopulation. In every other subpopulation and dose metric, the ratio was at most equal to 3 (neonates' RAM for 1,4-dioxane).

\subsection{HKAF Values}

3.2.1. "Whole Population" Approach. HKAFs determined based on the "whole population" approach, which used both the median adult $\left(\mathrm{HKAF}_{\mathrm{ad}}\right)$ and the median individual in the entire Canadian population $\left(\mathrm{HKAF}_{\mathrm{pop}}\right)$ as referents, are indicated in Table 5. CAss-based HKAFs varied between 1.2 and 1.3 for benzene and between 2.1 and 2.8 for 1,4dioxane. These values were slightly lower than the highest "distinct subpopulation-" based HKAFs for benzene but were significantly lower than the 1,4-dioxane values (see below). Considering the RAM, all the HKAF values were between 1.2 and 1.6 regardless of the chemical. These values were slightly lower than the highest RAM-based HKAFs obtained with the "distinct subpopulation" approach in pregnant women (1.52.1, see below).

3.2.2. "Distinct Subpopulation" Approach. Table 5 shows that the 95th and the 99th percentile-based HKAFs that were computed using the "distinct subpopulation" approach were comparable whether the median adult $\left(\mathrm{HKAF}_{\mathrm{ad}}\right)$ or the median individual in the whole population $\left(\mathrm{HKAF}_{\mathrm{pop}}\right)$ was used as a referent. In addition to the referent adults, results for neonates and pregnant women are presented because 


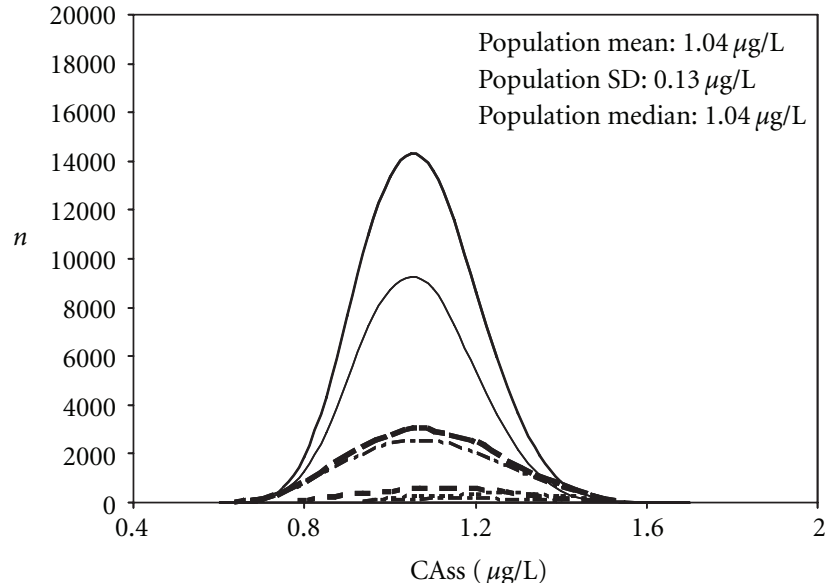

(a)

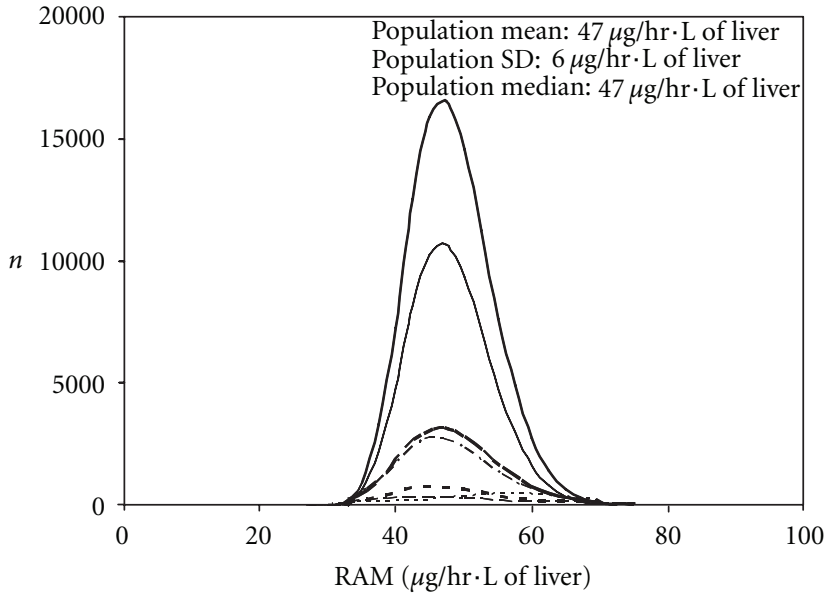

(b)

FIgure 1: Distributions of individual values obtained for CAss (a) and RAM (b) in each subpopulation within the whole Canadian population for constant inhalation exposure to benzene. From top to bottom, the distributions are shown for the entire Canadian population

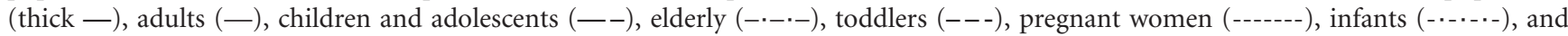
neonates (indistinguishable).

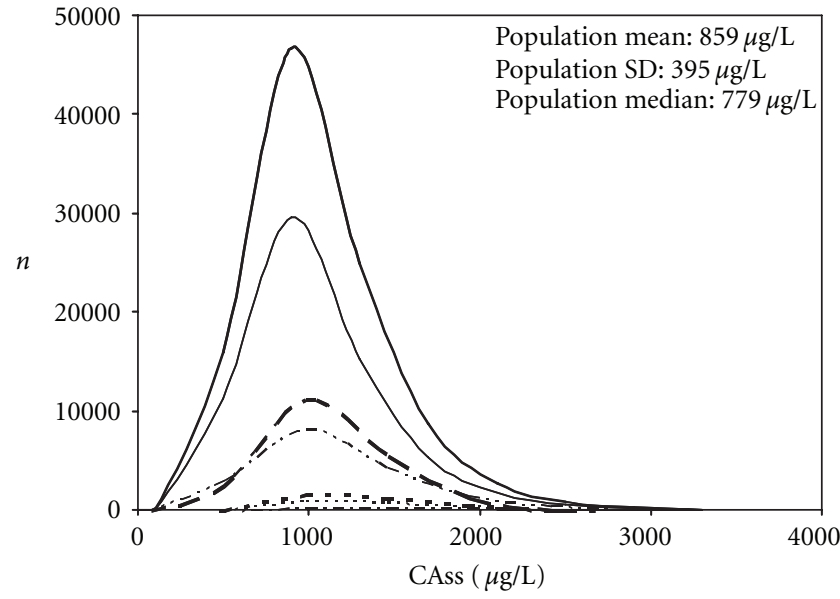

(a)

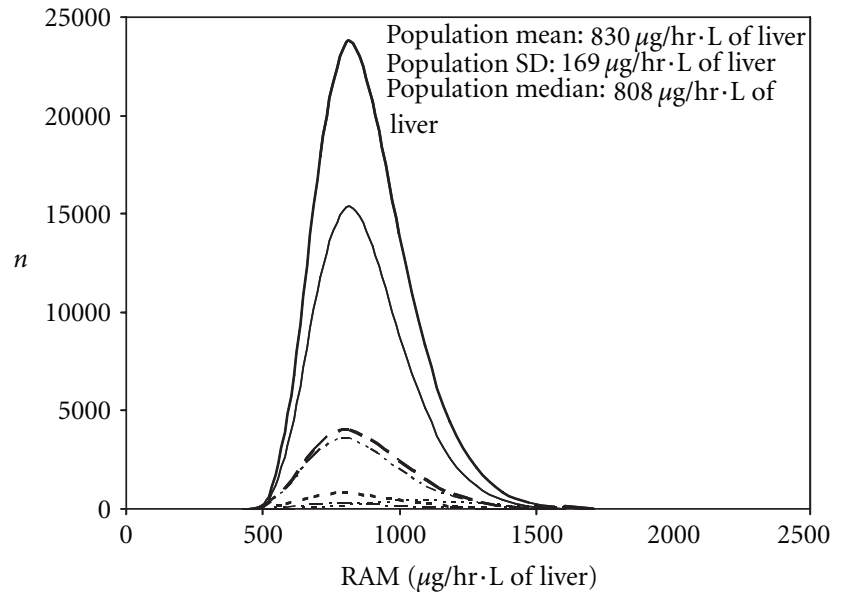

(b)

FIgURE 2: Distributions of individual values obtained for CAss (a) and RAM (b) in each subpopulation within the whole Canadian population for constant inhalation exposure to 1,4-dioxane. From top to bottom, the distributions are shown for the entire Canadian population (thick - ), adults (-), children and adolescents (--), elderly (-----), toddlers (---), pregnant women (-------), infants (-·-.$\cdot-$ ), and neonates (indistinguishable).

they were, toxicokinetically, the most susceptible based on their respective CAss and RAM (Table 4). HKAFs for infants were also shown because they exceeded the default 3.16 value when CAss of 1,4-dioxane was considered, on the basis of the 99th percentile value (3.8). The default value was also exceeded based only on CAss of 1,4-dioxane in neonates (range: $6.5-8.5$ ) and the 99th percentile value in pregnant women (3.5). Neonates exhibited the greatest CAssbased HKAFs for inhaled benzene (1.6-1.7). Otherwise, pregnant women showed the greatest RAM-based HKAFs for benzene (1.5-1.6) and 1,4-dioxane (1.8-2.1). HKAFs in other subpopulations remained in the range of the HKAFs presented in Table 5 for any given dose metric (data not shown).
3.3. Proportions of the Whole Population or the Distinct Subpopulations Covered by the Different HKAFs. Table 6 shows the proportion of each subpopulation that was covered by the various HKAFs defined using the "whole population" approach. The 95th or 99th percentile-based "whole population" HKAFs generally protect at least, or very close to, $95 \%$ and $99 \%$, respectively, of the individuals of each subpopulation. However, only $57 \%$ of the neonates, $78 \%$ of the pregnant women, and $89 \%$ of the infants were covered by the 95th percentile-based "whole population," CAss-based HKAF for benzene. Corresponding values for the 99th percentile-based HKAF values were $73 \%, 92 \%$, and $97 \%$, respectively. In the case of 1,4-dioxane, $27 \%, 76 \%$, and $86 \%$ of the neonates, infants, and pregnant women were 
TABle 4: Distribution statistics of various dose metrics in each subpopulation based on 100,000 Monte Carlo iterations and the entire Canadian populations for constant inhalation exposure.

\begin{tabular}{|c|c|c|c|c|}
\hline \multirow{3}{*}{$\begin{array}{l}\text { Subpopulation } \\
\text { Statistics }\end{array}$} & \multicolumn{4}{|c|}{ Dose metrics } \\
\hline & \multicolumn{2}{|c|}{ Benzene } & \multicolumn{2}{|c|}{ 1,4-Dioxane } \\
\hline & CAss & RAM & CAss & RAM \\
\hline \multicolumn{5}{|l|}{ Adults } \\
\hline 1st percentile & 0.76 & 35 & 285 & 531 \\
\hline Median & 1.04 & 46 & 763 & 806 \\
\hline 99th percentile & 1.36 & 62 & 2119 & 1291 \\
\hline \multicolumn{5}{|l|}{ Neonates } \\
\hline 1st percentile & 0.88 & 20 & 682 & 371 \\
\hline Median & 1.26 & 39 & 2299 & 686 \\
\hline 99th percentile & 1.76 & 55 & 6486 & 1149 \\
\hline \multicolumn{5}{|l|}{ Infants } \\
\hline 1st percentile & 0.8 & 33 & 420 & 526 \\
\hline Median & 1.11 & 45 & 1150 & 787 \\
\hline 99th percentile & 1.44 & 60 & 2928 & 1246 \\
\hline \multicolumn{5}{|l|}{ Toddlers } \\
\hline 1st percentile & 0.79 & 35 & 382 & 534 \\
\hline Median & 1.08 & 47 & 968 & 804 \\
\hline 99th percentile & 1.38 & 60 & 2099 & 1271 \\
\hline \multicolumn{5}{|c|}{ Children and adolescents } \\
\hline 1st percentile & 0.77 & 35 & 352 & 538 \\
\hline Median & 1.04 & 47 & 774 & 814 \\
\hline 99th percentile & 1.35 & 61 & 1744 & 1293 \\
\hline \multicolumn{5}{|l|}{ Elderly } \\
\hline 1st percentile & 0.76 & 35 & 286 & 530 \\
\hline Median & 1.04 & 46 & 766 & 807 \\
\hline 99th percentile & 1.37 & 62 & 2144 & 1291 \\
\hline \multicolumn{5}{|l|}{ Pregnant Women } \\
\hline 1st percentile & 0.85 & 41 & 372 & 673 \\
\hline Median & 1.16 & 55 & 995 & 1050 \\
\hline 99th percentile & 1.49 & 73 & 2698 & 1686 \\
\hline \multicolumn{5}{|c|}{ Canadian population } \\
\hline 1st percentile & 0.76 & 35 & 299 & 533 \\
\hline Median & 1.04 & 47 & 779 & 808 \\
\hline 99th percentile & 1.36 & 63 & 2139 & 1306 \\
\hline
\end{tabular}

CAss: blood concentration of parent compound $(\mu \mathrm{g} / \mathrm{L})$; RAM: rate of metabolism ( $\mu \mathrm{g} / \mathrm{h}-\mathrm{L}$ of liver).

covered by the 95th percentile-based HKAF, respectively. Corresponding values for the 99th percentile HKAFs were $48 \%, 92 \%$, and $96 \%$, respectively, and the default 3.16 factor appears to cover only $60 \%$ of the neonates. Considering the RAM, the lack of coverage by the "whole population-" based HKAF concerns pregnant women, as only $63 \%$ and $85 \%$ of them are covered by, respectively, the 95th and 99th percentile-based HKAF for benzene. These numbers are 66\% and $86 \%$ in the case of 1,4-dioxane. Finally, when the HKAF was computed with the "distinct subpopulation" approach and the greatest value was retained, more than $99 \%$ of the entire Canadian population was covered for every dose metric considered (Table 6).
3.4. Impact of the Demography on the Computed HKAFs. The impact of the demographic characteristics on the HKAF values as computed herein can be appreciated from the results shown in Figure 3 for CAss and Figure 4 for RAM. The distributions for 100,000 referents (adult) and the most susceptible individuals (neonates for CAss, pregnant women for RAM) are also shown in these figures for comparison purposes. For benzene (Figure 3(a)), the change in demographics did not impact the overall population distribution of CAss (indistinguishable from adults) and thus, not the HKAF. The change of demographics shifts minimally to the right the population distribution of CAss for 1,4-dioxane (Figure 3(b)). The impact on the various 
TABLE 5: HKAFs obtained by the "distinct subpopulation" approach on the basis of 100,000 Monte Carlo iterations in adults, neonates, infants, and pregnant women and by the "whole population" approach for the Canadian population.

\begin{tabular}{|c|c|c|c|c|}
\hline \multirow{3}{*}{ HKAF assumption } & \multicolumn{4}{|c|}{ Dose metrics } \\
\hline & \multicolumn{2}{|c|}{ Benzene } & \multicolumn{2}{|c|}{ 1,4-Dioxane } \\
\hline & CAss & RAM & CAss & RAM \\
\hline \multicolumn{5}{|l|}{ "Whole population" approach } \\
\hline \multicolumn{5}{|l|}{$\mathrm{HKAF}_{\mathrm{ad}}{ }^{(\mathrm{a})}$} \\
\hline Based on 95th percentile & 1.2 & 1.3 & 2.1 & 1.4 \\
\hline Based on 99th percentile & 1.3 & 1.4 & 2.8 & 1.6 \\
\hline \multicolumn{5}{|l|}{ HKAF $_{\text {pop }}{ }^{(b)}$} \\
\hline Based on 95th percentile & 1.2 & 1.2 & 2.1 & 1.4 \\
\hline Based on 99th percentile & 1.3 & 1.4 & 2.8 & 1.6 \\
\hline \multicolumn{5}{|l|}{ "Distinct subpopulation" approach } \\
\hline \multicolumn{5}{|l|}{ In adults } \\
\hline \multicolumn{5}{|l|}{$\mathrm{HKAF}_{\mathrm{ad}}{ }^{(\mathrm{c})}$} \\
\hline Based on 95th percentile & 1.2 & 1.2 & 2.1 & 1.4 \\
\hline Based on 99th percentile & 1.3 & 1.3 & 2.8 & 1.6 \\
\hline \multicolumn{5}{|l|}{$\mathrm{HKAF}_{\text {pop }}{ }^{(\mathrm{d})}$} \\
\hline Based on 95th percentile & 1.2 & 1.2 & 2.0 & 1.4 \\
\hline Based on 99th percentile & 1.3 & 1.3 & 2.7 & 1.6 \\
\hline \multicolumn{5}{|l|}{ In neonates } \\
\hline \multicolumn{5}{|l|}{$\mathrm{HKAF}_{\mathrm{ad}}^{(\mathrm{c})}$} \\
\hline Based on 95th percentile & 1.6 & 1.1 & 6.6 & 1.2 \\
\hline Based on 99th percentile & 1.7 & 1.2 & 8.5 & 1.4 \\
\hline \multicolumn{5}{|l|}{$\mathrm{HKAF}_{\text {pop }}{ }^{(\mathrm{d})}$} \\
\hline Based on 95th percentile & 1.6 & 1.1 & 6.5 & 1.2 \\
\hline Based on 99th percentile & 1.7 & 1.2 & 8.3 & 1.4 \\
\hline \multicolumn{5}{|l|}{ In infants } \\
\hline \multicolumn{5}{|l|}{$\mathrm{HKAF}_{\mathrm{ad}}{ }^{(\mathrm{c})}$} \\
\hline Based on 95th percentile & 1.3 & 1.2 & 3.1 & 1.4 \\
\hline Based on 99th percentile & 1.4 & 1.3 & 3.8 & 1.6 \\
\hline \multicolumn{5}{|l|}{$\mathrm{HKAF}_{\text {pop }}{ }^{(\mathrm{d})}$} \\
\hline Based on 95th percentile & 1.3 & 1.2 & 3.0 & 1.4 \\
\hline Based on 99th percentile & 1.4 & 1.3 & 3.8 & 1.5 \\
\hline \multicolumn{5}{|l|}{ In pregnant women } \\
\hline \multicolumn{5}{|l|}{$\mathrm{HKAF}_{\mathrm{ad}}{ }^{(\mathrm{c})}$} \\
\hline Based on 95th percentile & 1.4 & 1.5 & 2.7 & 1.8 \\
\hline Based on 99th percentile & 1.5 & 1.6 & 3.5 & 2.1 \\
\hline \multicolumn{5}{|l|}{$\mathrm{HKAF}_{\mathrm{pop}}{ }^{(\mathrm{d})}$} \\
\hline Based on 95th percentile & 1.4 & 1.5 & 2.6 & 1.8 \\
\hline Based on 99th percentile & 1.5 & 1.6 & 3.5 & 2.1 \\
\hline
\end{tabular}

Italicized values indicate the highest HKAF among each subpopulation for a given dose metric.

${ }^{(a)}$ Computed as the ratio of the upper percentile value in the Canadian population (95th or 99th) to the median in 100,000 adults. (b) Computed as the ratio of the upper percentile value in the Canadian population (95th or 99th) to its median. ${ }^{(\mathrm{c})}$ Computed as the ratio of the upper percentile value in the subpopulation (95th or 99th) to the median in adults. (d) Computed as the ratio of the upper percentile value in the subpopulation (95th or 99 th) to the median in the Canadian population.

CAss: blood concentration of parent compound; $\operatorname{HKAF}_{(\mathrm{ad} / \mathrm{pop})}$ : human kinetic adjustment factor using either the median in adult ("ad") or whole population ("pop") as referent; RAM: rate of metabolism. 
TABLE 6: Percentage of individuals in the diverse Canadian subpopulations that are covered by the HKAF and the default factor for various dose metrics and chemicals.

\begin{tabular}{|c|c|c|c|c|}
\hline \multirow[t]{3}{*}{ Subpopulation Variability descriptor } & \multicolumn{4}{|c|}{ Dose metrics } \\
\hline & \multicolumn{2}{|c|}{ Benzene } & \multicolumn{2}{|c|}{ 1,4-Dioxane } \\
\hline & CAss (\%) & RAM (\%) & CAss (\%) & RAM (\%) \\
\hline \multicolumn{5}{|l|}{ Adults } \\
\hline “whole population"(a) $\mathrm{HKAF}_{95 \text { th }}$ & 96 & 96 & 95 & 97 \\
\hline "whole population"(a) $\mathrm{HKAF}_{99 t h}$ & 99 & $>99$ & $>99$ & $>99$ \\
\hline Default 3.16 factor & 100 & 100 & $>99$ & 100 \\
\hline \multicolumn{5}{|l|}{ Neonates } \\
\hline "whole population"(a) $\mathrm{HKAF}_{95 \text { th }}$ & 57 & 100 & 27 & 100 \\
\hline "whole population"(a) $\mathrm{HKAF}_{99 \mathrm{th}}$ & 73 & 100 & 48 & 100 \\
\hline Default 3.16 factor & 100 & 100 & 60 & 100 \\
\hline \multicolumn{5}{|l|}{ Infants } \\
\hline "whole population"(a) $\mathrm{HKAF}_{95 \text { th }}$ & 89 & 97 & 76 & 97 \\
\hline "whole population"(a) $\mathrm{HKAF}_{99 t h}$ & 97 & $>99$ & 92 & $>99$ \\
\hline Default 3.16 factor & 100 & 100 & 97 & 100 \\
\hline \multicolumn{5}{|l|}{ Toddlers } \\
\hline "whole population"(a) $\mathrm{HKAF}_{95 \text { th }}$ & 93 & 97 & 92 & 96 \\
\hline "whole population"(a) $\mathrm{HKAF}_{99 t h}$ & 99 & $>99$ & 99 & 99 \\
\hline Default 3.16 factor & 100 & 100 & $>99$ & 100 \\
\hline \multicolumn{5}{|l|}{ Children and adolescents } \\
\hline "whole population"(a) $\mathrm{HKAF}_{95 \text { th }}$ & 96 & 96 & 98 & 95 \\
\hline "whole population"(a) $\mathrm{HKAF}_{99 t h}$ & $>99$ & $>99$ & $>99$ & $>99$ \\
\hline Default 3.16 factor & 100 & 100 & 100 & 100 \\
\hline \multicolumn{5}{|l|}{ Elderly } \\
\hline "whole population"(a) $\mathrm{HKAF}_{95 \text { th }}$ & 95 & 96 & 95 & 96 \\
\hline "whole population"(a) $\mathrm{HKAF}_{99 t h}$ & $>99$ & 99 & 99 & $>99$ \\
\hline Default 3.16 factor & 100 & 100 & $>99$ & 100 \\
\hline \multicolumn{5}{|l|}{ Pregnant Women } \\
\hline "whole population"(a) $\mathrm{HKAF}_{95 \text { th }}$ & 78 & 63 & 86 & 66 \\
\hline “whole population"(a) $\mathrm{HKAF}_{99 t h}$ & 92 & 85 & 96 & 86 \\
\hline Default 3.16 factor & 100 & 100 & 98 & 100 \\
\hline \multicolumn{5}{|l|}{ Canadian population } \\
\hline Greatest $^{(\mathrm{b})}$ "distinct subpopulation" $\mathrm{HKAF}_{95 \mathrm{th}}$ & $>99$ & $>99$ & $>99$ & $>99$ \\
\hline Greatest $^{(\mathrm{b})}$ "distinct subpopulation" $\mathrm{HKAF}_{99 \mathrm{th}}$ & $>99$ & $>99$ & $>99$ & $>99$ \\
\hline Default 3.16 factor & 100 & 100 & $>99$ & 100 \\
\hline
\end{tabular}

(a) Based on the median value in the whole Canadian population. ${ }^{(b)}$ Based on the median value in adults in Table 5.

CAss: blood concentration of parent compound $(\mu \mathrm{g} / \mathrm{L})$; RAM: rate of metabolism ( $\mu \mathrm{g} / \mathrm{h}-\mathrm{L}$ of liver).

HKAFs was low ("whole population" HKAF $=2.69$ versus 2.75 ) with differences of $3 \%$ or less for the relevant statistical descriptors. Considering RAM, when the number of significantly less susceptible neonates, and infants, and more susceptible pregnant women, was increased at the expense of adults, the entire population distribution of the dose metric for both chemicals was widened slightly and particularly for 1,4-dioxane (Figure 4). The impact of pregnant women was apparent with a slight burst in the "younger" population distribution, which was observed near the pregnant women's approximate median value. On the basis of the 99th percentile values, this resulted in virtually unchanged HKAFs for benzene (Figure 4(a)), but marginal changes were observed for 1,4-dioxane (Figure 4(b)). The "whole population" HKAFs that were calculated from the indicated statistical descriptors are 1.67 (1342/806) and 1.75 (1342/765), which were based on median values in adults or population distributions, respectively, for the "younger" population. In comparison, the "whole population" HKAF for the Canadian population was 1.62. The "distinct subpopulation" HKAF for pregnant women was also slightly increased, from 2.09 for the Canadian and adult populations to 2.2 for the "younger" population due to lower median values $(765 \mu \mathrm{g} / \mathrm{h}-\mathrm{L}$ of liver versus 808 or $806 \mu \mathrm{g} / \mathrm{h}-\mathrm{L}$ of liver). 


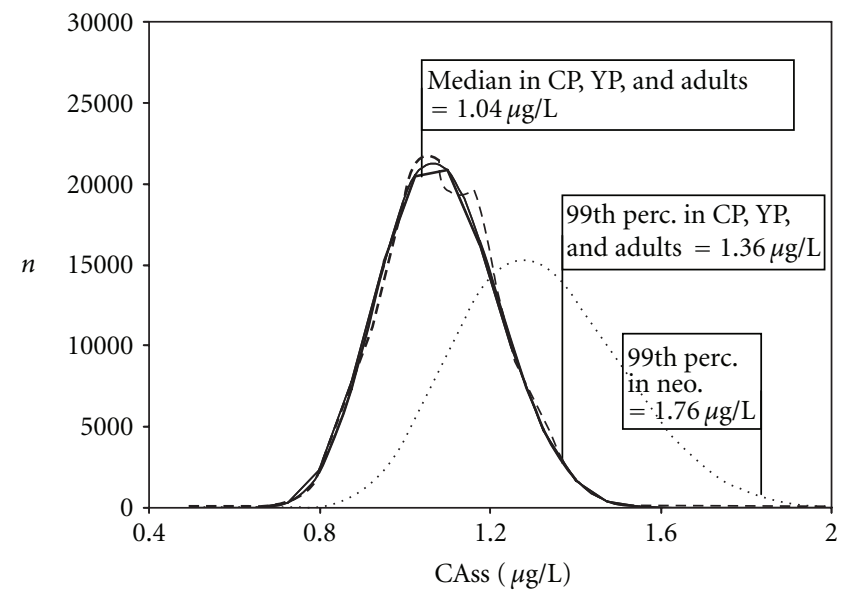

(a)

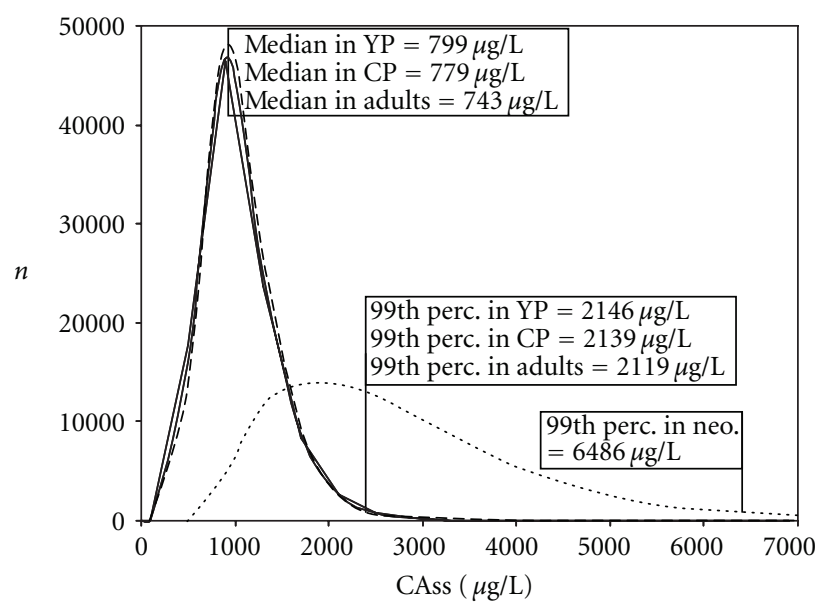

(b)

Figure 3: Distribution of individual values obtained for CAss for constant inhalation exposure to benzene (a) and 1,4-dioxane (b) in the entire Canadian (CP, thick - ) and "younger" (YP, --) populations of 100,000 people, in 100,000 adults (-) and in 100,000 of the most susceptible neonates $($ neo, ...). Median and 99th percentile values only (for clarity reasons) are indicated.

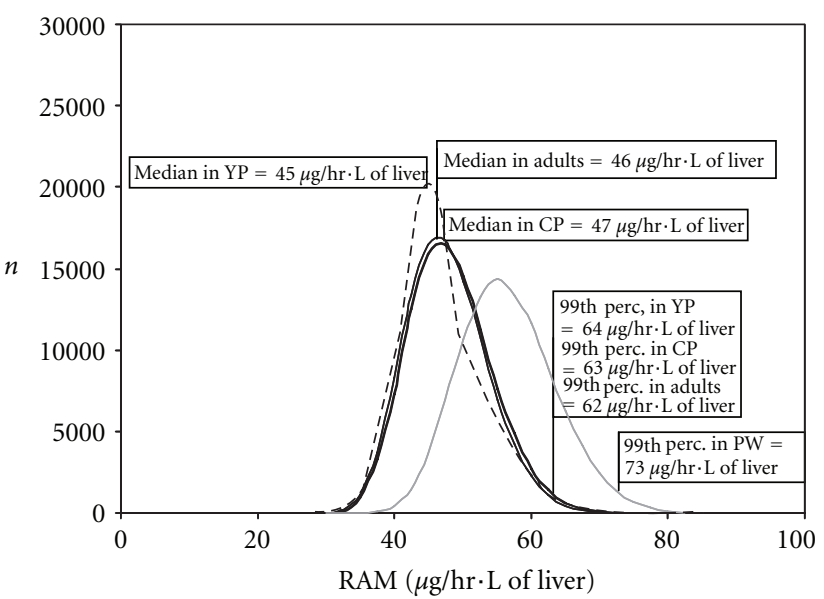

(a)

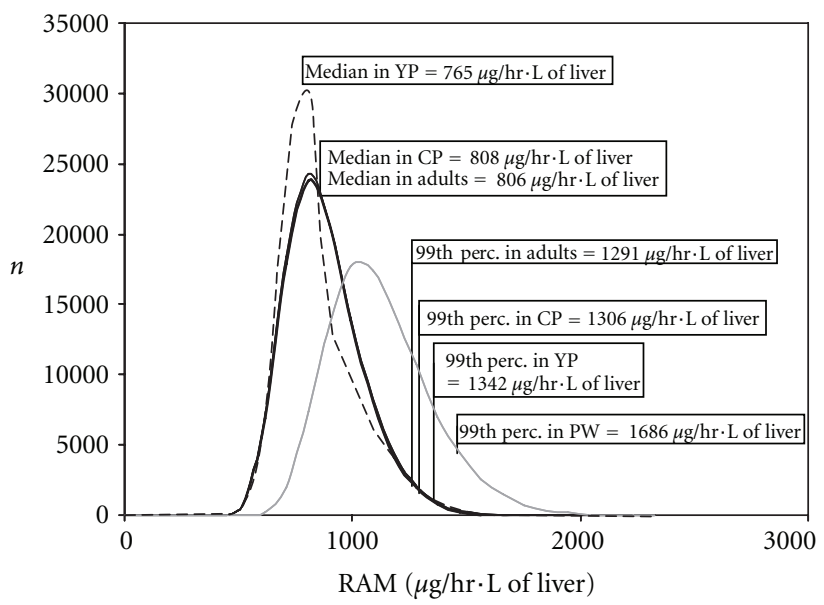

(b)

FIGURE 4: Distribution of individual values obtained for RAM for constant inhalation exposure to benzene (a) and 1,4-dioxane (b) in the entire Canadian (CP, thick - ), and "younger" (YP, - -) populations of 100,000 people, in 100,000 adults (-) and in 100,000 of the most susceptible pregnant women (PW, grey -).

\section{Discussion}

This study performed Monte Carlo simulations on a steadystate algorithm to reconstruct representative subpopulation and whole population distributions of internal dose metrics for continuous inhalation exposure to a highly (benzene) and poorly (1,4-dioxane) cleared chemical. This allowed evaluating the impact of various assumptions on the resulting HKAF.

Virtual populations have been reconstructed to evaluate the population variability of the pharmacokinetic of drugs (e.g., $[32,33])$, but to date, the same approach had not been realized for environmental contaminants. This procedure realized in the context of the present study allowed obtaining results showing that the impact of the approach chosen to compute the HKAF depends on the chemical and dose metric considered. The "whole population" approach used here can be related to the "Finite Sample Size" model of IVF from Price et al. [4], whereas the "distinct subpopulation-" based HKAF can be associated to these authors' "sensitive population" model. When the most sensitive individuals, based on dosimetric considerations, constitute a very small fraction of the entire population, a "whole population-" based HKAF might not be sufficient to cover them adequately. For instance, less than $60 \%$ of the neonates, constituting less than $0.1 \%$ of the whole Canadian population in this study, were covered by the "whole population" HKAF based on their 95th percentile CAss value. This was also the case of infants, who constituted a mere $1 \%$ of the entire population, for whom less than $90 \%$ of the individuals 
simulated were covered by that same HKAF (Table 6). The reasons for these results can be determined from Figures 1 and 2. Because toxicokinetically sensitive neonates and infants make up a small proportion of the population, their CAss values do not stand out at the right end of the whole population distributions (Figures 1(a) and 2(a)). Thus, the "distinct subpopulation-" based HKAF would appear to be more adequate in these cases because the focus is then put on the most sensitive subpopulations, regardless of whether the data follow unimodal or bimodal distributions. Conversely, when the more sparse individuals (neonates and infants) are rather less sensitive than the vast majority of the individuals composing the entire population, as for RAM, the approach taken to compute the HKAF does not impact its value (Table 5).

The results obtained in Figures 3 and 4 can be viewed as a "sensitivity analysis" of the impact of demography on the HKAF. Replacing a significant number of adults from the Canadian population with individuals who are generally equally susceptible as adults (Table 4) resulted in a "younger" population distribution of CAss for benzene that remained virtually unchanged (Figure 3(a)). In the case of 1,4-dioxane (Figure 3(b)), every replacing individual pertained to subpopulations that were more susceptible than adults (Table 4), and, as a result, the population distribution of CAss slightly shifted to the right towards the most susceptible neonates. In the case of RAM, the individuals replacing the adults were either more susceptible (pregnant women) or less susceptible (children), leading to population distributions that were wider for both chemicals (Figure 4). As mentioned in Section 3, the sensitivity of the HKAF to the population demography (i.e., the impact of the population distribution shift on the estimated HKAF) was marginal because the differences in the susceptibilities were not very pronounced between the subpopulations, with the exceptions of neonates and infants based on CAss (particularly for 1,4-dioxane), and pregnant women based on the RAM. However, the impact of these subpopulations' dose metric on the entire population distribution always remained minimal because of their small percentage in the entire population.

While in our study, demography appears to have, at the most, a very marginal effect on HKAF, the population distributions of CAss are conversely significantly influenced by the determining physiological parameters. Indeed, intake and pulmonary clearance of both benzene and 1,4-dioxane are driven by alveolar ventilation rate, which is rather log normally distributed when adjusted to the body weight (Figure 5(a)). However, blood-flow limited metabolism results in hepatic blood flow being the determining parameter for the clearance of benzene whereas for 1,4-dioxane, hepatic enzyme concentration and thus $V \max$ (see (4)) is determinant of its enzyme-limited clearance. As a result, the distribution of body-weight-adjusted liver blood flow (Figure 5(b)), which is more skewed than the distributions of $V \max$ (Figure 5(c)) or Clint (central tendency, range: $\approx 400 \mathrm{~L} / \mathrm{h}, 0-1600 \mathrm{~L} / \mathrm{h}$ ), yields a population distribution of CAss that is more skewed for benzene (Figure 1(a)) than for 1,4-dioxane (Figure 2(a)). Indeed, the hepatic clearance of the latter is rather driven by the $V \max$ (Figure $5(d)$ ) and the corresponding Clint (central tendency, range: $\approx 1.7 \mathrm{~L} / \mathrm{h}, 0$ $7 \mathrm{~L} / \mathrm{h}$ ). Correspondingly, "whole population-" based HKAFs are smaller for benzene than 1,4-dioxane (Table 5).

The toxicokinetic determinants, including physiological parameters, of the susceptibility of each subpopulation to a given chemical based on any dose metric have been thoroughly discussed elsewhere [16]. Briefly, neonates are the most susceptible population based on CAss (Table 5) because they are exposed to a greater-than-adult bodyweight-adjusted dose by inhalation, or to a poorly metabolized chemical (1,4-dioxane) for which hepatic metabolism is enzyme-limited, thus reduced in neonates. For pregnant women, their greater susceptibility on the basis of RAM is due to their increased intake on a body weight basis (due to high Qp) combined with their efficient hepatic clearance, a combination that yields a high rate of conversion of inhaled parent compound into metabolites. Greater inhalation uptake on a body weight basis and corresponding blood concentration of inhaled VOCs, for young children and pregnant women as compared to adults, have been consistently documented and discussed in the literature [14$16,29,34-39]$. The systemic clearance of high $P_{b}$, poorly metabolized 1,4-dioxane is Qp-dependent (for pulmonary clearance) and enzyme-dependent (for hepatic clearance), and the greater intrasubpopulation variability of CAss that was observed for this chemical was expected. This greater variability results in neonates and infants constituting the only subpopulation for which the consideration of the 99th percentile value rather than the 95th significantly changes their HKAF value (Table 5). Else, the intra-subpopulation variability was rather low for every dose metric.

The "distinct subpopulation-" based $\mathrm{HKAF}_{\mathrm{ad}}$ that was obtained for benzene exposure in infants (1.3-1.4, Table 5) and toddlers (1.25-1.33, not shown) was very similar to the values obtained for other inhaled VOCs by Pelekis et al. [40] for a $10 \mathrm{~kg}$ child. Using a deterministic steady-state approach, these authors obtained an average factor of $1.1 \pm$ 0.6 for eight chemicals highly cleared by either pulmonary or hepatic clearance or both. Also, a ratio of the neonate's 95th percentile value to the adult's median value of blood concentrations for dichloromethane was slightly above 2 in the study by Pelekis et al. [41] for continuous inhalation exposure, as compared to 1.6 for benzene in the current study. Besides, the "distinct subpopulation-" based HKAF pop that was obtained in neonates for 1,4-dioxane (6.5, Table 5) was markedly greater than the value (2) obtained by Mörk and Johanson [17] for acetone, a chemical that is similar to 1,4-dioxane (poorly metabolized and highly water soluble with a $P_{b}$ of 260). The HKAF obtained for 1,4-dioxane in children and adolescents (1.8, not shown) is comparable to those obtained by these authors for 10 and $15 \mathrm{yr}$ old children for acetone (1.7-2.4). The discrepancy for neonates might be explained by the difference in the mean age considered (14 days versus 3 months) and related hepatic enzyme content. The "whole population-" based HKAF pop obtained here based on the 95th percentile (2.1) compares well to Mörk and Johanson's results (i.e., 1.9). Finally, Renwick and Lazarus [7] determined that more than $99 \%$ of individuals in 


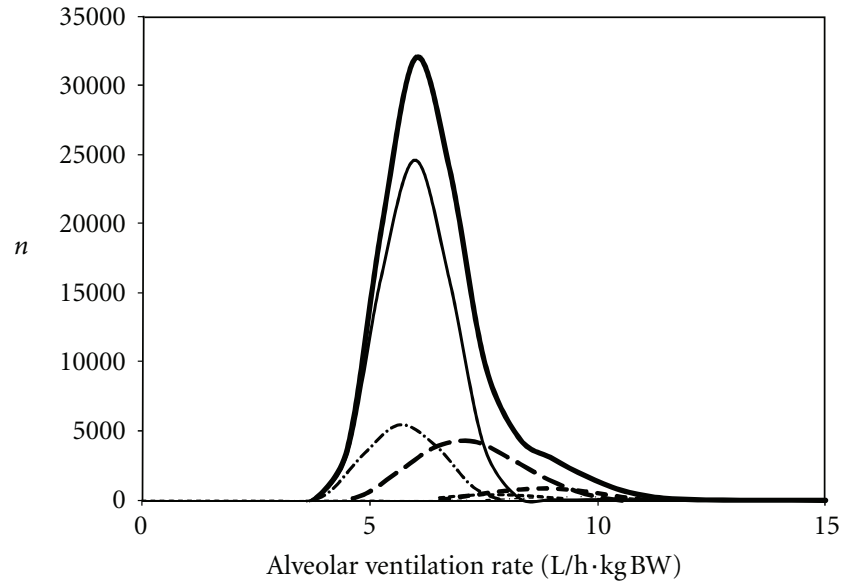

(a)

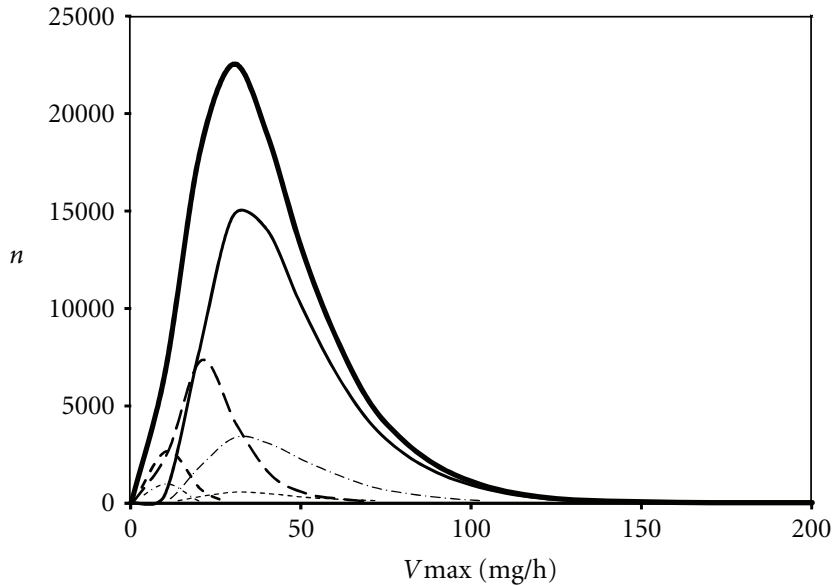

(c)

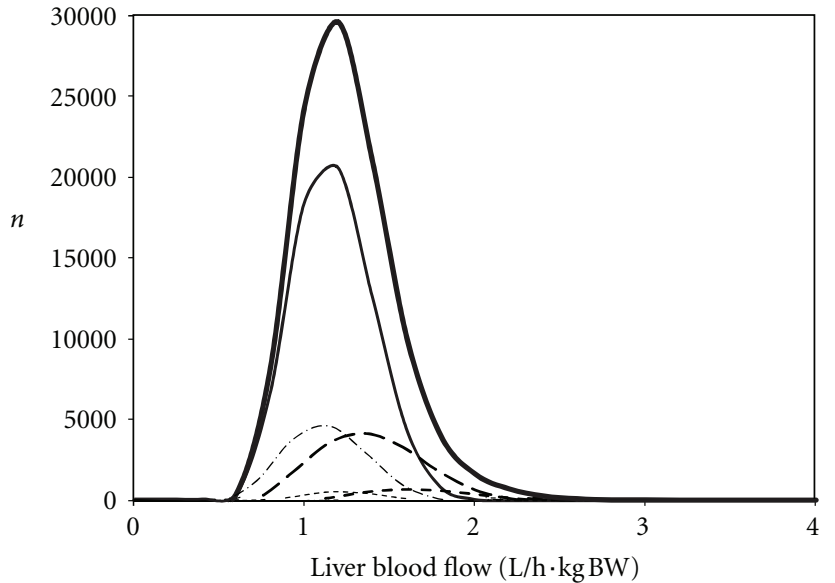

(b)

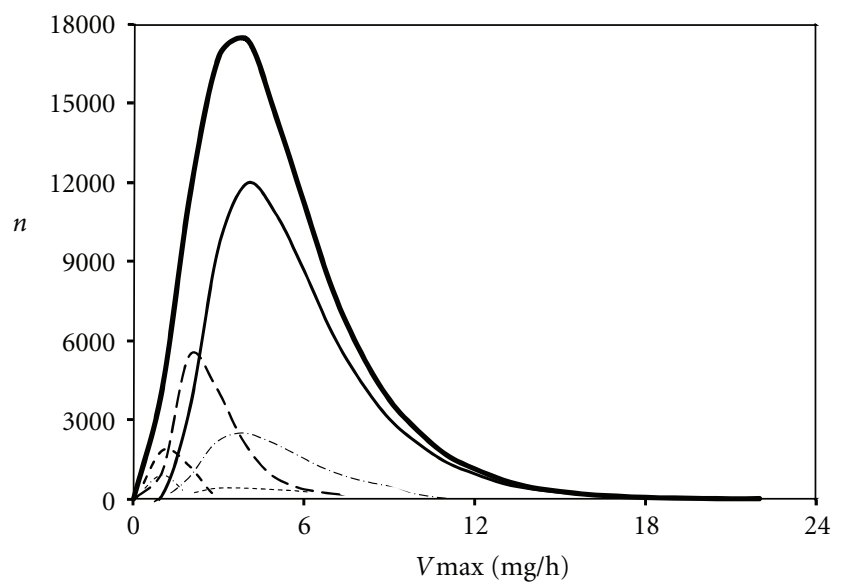

(d)

FIGURE 5: Distributions of individual values obtained for several physiological parameters in each subpopulation within the whole virtual Canadian population. From top to bottom, distributions for body weight-adjusted alveolar ventilation rate (a), body weight-adjusted liver blood flow (b) and maximal rate of metabolism of benzene (c) and 1,4-dioxane (d) are shown for the entire Canadian population ( thick - ), adults $(-)$, children and adolescents $(--)$, elderly $(-\cdot-\cdot-)$, toddlers $(---)$, pregnant women $(--\cdot-\cdot-)$, infants $(-\cdot \cdot \cdot \cdot \cdot-)$, and neonates (indistinguishable).

a theoretical population of 1 million would be covered by the default factor, a proportion also obtained in this study.

Among the limitations of this study are other demographic characteristics, including gender differentiation, that could have been considered when generating the population distributions. In particular, ethnicity can be a critical determinant of population variability in toxicokinetics [7] because it is often linked to polymorphic metabolism [42]. However, multiplying subpopulation categories would increase the uncertainty linked to analyzing the distribution of the dose metric in very rare individuals like those with genetic polymorphisms. Besides, gender-related differences in the blood toxicokinetics of several VOCs have been considered insignificant $[38,43]$. Furthermore, ethnicity is likely not a primary factor determining CYP2E1 activity because the population variability in the enzyme expression caused by factors other than polymorphism, such as ethanol consumption and xenobiotic coexposure [44] is considerable. Another limitation relates to the use of only healthy individuals in this study; the HKAFs calculated thus do not account for diseased people with altered hepatic or extrahepatic clearance.

In conclusion, this study has, for the first time, systematically compared different approaches for computing the HKAF under various assumptions related to the population/subpopulation variability in internal dose metric for continuous inhalation exposure. This was determined for two environmental chemicals exhibiting different patterns of systemic clearance, to encompass a range of other potential chemicals with such characteristics. This study contributes to clarify the implications of the different underlying assumptions that relate to the interindividual variability considered when determining the HKAF for any risk management consideration, including adequate coverage or not of the most susceptible, but sparse, individuals of a given population. In this regard, relying on the "distinct subpopulation" approach appears more conservative (protective) as it better covers the most susceptible individuals, in particular if they compose a small proportion of the general population. 
Fundamentally, the difference in the extent of coverage afforded by these two approaches would appear to depend upon the proportion of the most sensitive individuals in the target population for a risk assessment. Moreover, the present work has illustrated the feasibility of a novel approach for characterizing demography-based population variability of internal dose metrics for environmental contaminants.

\section{Abbreviations}

\begin{tabular}{|c|c|}
\hline CSAF: & Chemical-specific adjustment factor \\
\hline CAss: & $\begin{array}{l}\text { Arterial blood concentration at } \\
\text { steady-state }\end{array}$ \\
\hline CYP: & Cytochrome P-450 \\
\hline HKAF: & Human kinetic adjustment factor \\
\hline $\operatorname{HKAF}_{(\mathrm{ad} / \mathrm{po}}$ & $\begin{array}{l}\text { Human kinetic adjustment factor using } \\
\text { as referent the median in either the } \\
\text { adults (ad) or in the population (pop) }\end{array}$ \\
\hline IVF: & $\begin{array}{l}\text { Interindividual variability uncertainty } \\
\text { factor }\end{array}$ \\
\hline Km: & Michaelis-Menten constant \\
\hline$P_{b}:$ & Blood : air partition coefficient \\
\hline PBPK: & Physiologically based pharmacokinetic \\
\hline POD: & Point of departure \\
\hline Q1: & Liver blood flow \\
\hline Qp: & Alveolar ventilation rate \\
\hline RAM: & Rate of metabolism \\
\hline RfC: & Reference concentration \\
\hline RfD: & Reference dose \\
\hline$V \max :$ & Maximum rate of metabolism \\
\hline Vl: & Volume of liver \\
\hline VOC: & Volatile organic compound. \\
\hline
\end{tabular}

\section{Acknowledgment}

Financial support from the Programme stratégique de formation des IRSC et du RRSPQ en recherche transdisciplinaire sur les interventions de santé publique: Promotion, Prévention et Politiques Publiques (4P) is acknowledged (M. Valcke). Dr. A. Nong's current address is Environmental Health Science and Research Bureau, Health Canada, Ottawa, ON, Canada K1A 0K9.

\section{References}

[1] M. L. Dourson, S. P. Felter, and D. Robinson, "Evolution of science-based uncertainty factors in noncancer risk assessment," Regulatory Toxicology and Pharmacology, vol. 24, no. 2, pp. 108-120, 1996.

[2] M. L. Dourson and J. F. Stara, "Regulatory history and experimental support of uncertainty (safety) factors," Regulatory Toxicology and Pharmacology, vol. 3, no. 3, pp. 224-238, 1983.

[3] U.S.EPA., A review of the reference dose and reference concentration process. Risk Assessment Forum. EPA/630/P02/00F. Washington, DC, USA, 2002.

[4] P. S. Price, R. E. Keenan, and B. Schwab, "Defining the interindividual (intraspecies) uncertainty factor," Human and Ecological Risk Assessment, vol. 5, no. 5, pp. 1023-1033, 1999.

[5] J. L. C. M. Dorne and A. G. Renwick, "The refinement of uncertainty/safety factors in risk assessment by the incor- poration of data on toxicokinetic variability in humans," Toxicological Sciences, vol. 86, no. 1, pp. 20-26, 2005.

[6] IPCS, Assessing Human Health Risks of Chemicals: Derivation of Guidance Values for Health Based Exposure Limits, World Health Organization, International Panel on Chemical Safety. Environmental Health Criteria, Geneva, Switzerland, 1994.

[7] A. G. Renwick and N. R. Lazarus, "Human variability and noncancer risk assessment-an analysis of the default uncertainty factor," Regulatory Toxicology and Pharmacology, vol. 27, no. 1 I, pp. 3-20, 1998.

[8] IPCS, Chemical-Specific Adjustment Factors (CSAFs) for Interspecies Differences and Human Variability: Guidance Document for the Use of Data in Dose/Concentration-Response Assessment, WHO, Geneva, Switzerland, 2005.

[9] M. E. Meek, A. Renwick, E. Ohanian et al., "Guidelines for application of chemical-specific adjustment factors in dose/concentration-response assessment," Toxicology, vol. 181-182, pp. 115-120, 2002.

[10] U.S.EPA., Integrated Risk Information System. U.S. Environmental Protection Agency, Washington, DC, USA, 2010.

[11] G. Ginsberg, D. Hattis, B. Sonawane et al., "Evaluation of child/adult pharmacokinetic differences from a database derived from the therapeutic drug literature," Toxicological Sciences, vol. 66, no. 2, pp. 185-200, 2002.

[12] J. L. C. M. Dorne, K. Walton, and A. G. Renwick, "Human variability in xenobiotic metabolism and pathway-related uncertainty factors for chemical risk assessment: a review," Food and Chemical Toxicology, vol. 43, no. 2, pp. 203-216, 2005.

[13] J. L. C. M. Dorne, "Human variability in hepatic and renal elimination: implications for risk assessment," Journal of Applied Toxicology, vol. 27, no. 5, pp. 411-420, 2007.

[14] A. Nong, D. G. McCarver, R. N. Hines, and K. Krishnan, "Modeling interchild differences in pharmacokinetics on the basis of subject-specific data on physiology and hepatic CYP2E1 levels: a case study with toluene," Toxicology and Applied Pharmacology, vol. 214, no. 1, pp. 78-87, 2006.

[15] M. Valcke and K. Krishnan, "Evaluation of the impact of the exposure route on the human kinetic adjustment factor," Regulatory Toxicology and Pharmacology, vol. 59, no. 2, pp. 258-269, 2011.

[16] M. Valcke and K. Krishnan, "An assessment of the impact of physico-chemical and biochemical characteristics on the human kinetic adjustment factor for systemic toxicants," Toxicology, vol. 286, no. 1-3, pp. 36-47, 2011.

[17] A. K. Mörk and G. Johanson, "Chemical-specific adjustment factors for intraspecies variability of acetone toxicokinetics using a probabilistic approach," Toxicological Sciences, vol. 116, no. 1, pp. 336-348, 2010.

[18] M. J. J. Ronis, K. O. Lindros, and M. Ingelman-Sundberg, "The CYP2E family," in Cytochrome P450 Metabolic and Toxicological Aspects, C. Ioannides, Ed., pp. 211-240, CRC Press, Boca Raton, Fla, USA, 1996.

[19] E. K. Johnsrud, S. B. Koukouritaki, K. Divakaran, L. L. Brunengraber, R. N. Hines, and D. G. McCarver, "Human hepatic CYP2E1 expression during development," Journal of Pharmacology and Experimental Therapeutics, vol. 307, no. 1, pp. 402-407, 2003.

[20] J. C. Lipscomb, L. K. Teuschler, J. C. Swartout, C. A. F. Striley, and J. E. Snawder, "Variance of microsomal protein and cytochrome P450 2E1 and 3A forms in adult human liver," Toxicology Mechanisms and Methods, vol. 13, no. 1, pp. 45-51, 2003. 
[21] A. Nannelli, A. De Rubertis, V. Longo, and P. G. Gervasi, "Effects of dioxane on cytochrome P450 enzymes in liver, kidney, lung and nasal mucosa of rat," Archives of Toxicology, vol. 79, no. 2, pp. 74-82, 2005.

[22] S. Haddad, M. Béliveau, R. Tardif, and K. Krishnan, "A PBPK modeling-based approach to account for interactions in the health risk assessment of chemical mixtures," Toxicological Sciences, vol. 63, no. 1, pp. 125-131, 2001.

[23] R. H. Reitz, P. S. McCroskey, C. N. Park, M. E. Andersen, and M. I. Gargas, "Development of a physiologically based pharmacokinetic model for risk assessment with 1,4-dioxane," Toxicology and Applied Pharmacology, vol. 105, no. 1, pp. 3754, 1990.

[24] M. E. Andersen, "Pharmacokinetics of inhaled gases and vapors," Neurobehavioral Toxicology and Teratology, vol. 3, no. 4, pp. 383-389, 1981.

[25] W. A. Chiu and P. White, "Steady-state solutions to PBPK models and their applications to risk assessment I: route-toroute extrapolation of volatile chemicals," Risk Analysis, vol. 26, no. 3, pp. 769-780, 2006.

[26] G. A. Csanády and J. G. Filser, "The relevance of physical activity for the kinetics of inhaled gaseous substances," Archives of Toxicology, vol. 74, no. 11, pp. 663-672, 2001.

[27] M. Pelekis, D. Krewski, and K. Krishnan, "Physiologically based algebraic expressions for predicting steady-state toxicokinetics of inhaled vapors," Toxicology Methods, vol. 7, no. 3, pp. 205-225, 1997.

[28] P. S. Price, R. B. Conolly, C. F. Chaisson et al., "Modeling interindividual variation in physiological factors used in PBPK models of humans," Critical Reviews in Toxicology, vol. 33, no. 5, pp. 469-503, 2003.

[29] ICRP, "Basic anatomical and physiological data for use in radiological protection: reference values. A report of age- and gender-related differences in the anatomical and physiological characteristics of reference individuals. ICRP Publication 89," Annals of the ICRP, vol. 32, no. 3-4, pp. 5-265, 2002.

[30] Statistiques Canada, Estimations de la population selon le sexe et le groupe d'âge au 1er juillet 2010, Canada http://www .statcan.gc.ca/daily-quotidien/100929/t100929b4-fra.htm.

[31] S. J. Ventura, J. C. Abma, W. D. Mosher, and S. K. Henshaw, "Estimated pregnancy rates by outcome for the United States, 1990-2004," National Vital Statistics Reports, vol. 56, no. 15, pp. 1-28, 2008.

[32] M. Jamei, G. L. Dickinson, and A. Rostami-Hodjegan, "A framework for assessing inter-individual variability in pharmacokinetics using virtual human populations and integrating general knowledge of physical chemistry, biology, anatomy, physiology and genetics: a tale of 'bottom-up' vs 'top-down' recognition of covariates," Drug Metabolism and Pharmacokinetics, vol. 24, no. 1, pp. 53-75, 2009.

[33] S. F. Hudachek and D. L. Gustafson, "Customized in silico population mimics actual population in docetaxel population pharmacokinetic analysis," Journal of Pharmaceutical Sciences, vol. 100, no. 3, pp. 1156-1166, 2011.

[34] P. Brochu, J. F. Ducré-Robitaille, and J. Brodeur, "Physiological daily inhalation rates for free-living pregnant and lactating adolescents and women aged 11 to 55 years, using data from doubly labeled water measurements for use in health risk assessment," Human and Ecological Risk Assessment, vol. 12, no. 4, pp. 702-735, 2006.

[35] P. Brochu, J. Brodeur, and K. Krishnan, "Derivation of physiological inhalation rates in children, adults, and elderly based on nighttime and daytime respiratory parameters," Inhalation Toxicology, vol. 23, no. 2, pp. 74-94, 2011.
[36] E. M. Faustman and P. Ribeiro, "Pharmacokinetic consideration in developmental toxicity," in Developmental Toxicology: Risk Assessment and the Future, R. D. Hood, Ed., pp. 109-136, D. Van Nostrand Reinhold Company, New York, NY, USA, 1990.

[37] K. Price, S. Haddad, and K. Krishnan, "Physiological modeling of age-specific changes in the pharmacokinetics of organic chemicals in children," Journal of Toxicology and Environmental Health-Part A, vol. 66, no. 5, pp. 417-433, 2003.

[38] R. Sarangapani, P. Robinan Gentry, T. R. Covington, J. G. Teeguarden, and H. J. Clewell, "Evaluation of the potential impact of age- and gender-specific lung morphology and ventilation rate on the dosimetry of vapors," Inhalation Toxicology, vol. 15, no. 10, pp. 987-1016, 2003.

[39] WHO, Principles for Evaluating Health Risks in Children Associated with Exposure to Chemicals, Environmental Health Criteria 237, World Health Organization, Geneva, Switzerland, 2006.

[40] M. Pelekis, L. A. Gephart, and S. E. Lerman, "Physiologicalmodel-based derivation of the adult and child pharmacokinetic intraspecies uncertainty factors for volatile organic compounds," Regulatory Toxicology and Pharmacology, vol. 33, no. 1, pp. 12-20, 2001.

[41] M. Pelekis, M. J. Nicolich, and J. S. Gauthier, "Probabilistic framework for the estimation of the adult and child toxicokinetic intraspecies uncertainty factors," Risk Analysis, vol. 23, no. 6, pp. 1239-1255, 2003.

[42] L. T. Haber, A. Maier, P. R. Gentry, H. J. Clewell, and M. L. Dourson, "Genetic polymorphisms in assessing interindividual variability in delivered dose," Regulatory Toxicology and Pharmacology, vol. 35, no. 2 I, pp. 177-197, 2002.

[43] H. J. Clewell, P. R. Gentry, T. R. Covington, R. Sarangapani, and J. G. Teeguarden, "Evaluation of the potential impact of age- and gender-specific pharmacokinetic differences on tissue dosimetry," Toxicological Sciences, vol. 79, no. 2, pp. 381-393, 2004.

[44] P. Neafsey, G. Ginsberg, D. Hattis, D. O. Johns, K. Z. Guyton, and B. Sonawane, "Genetic polymorphism in CYP2E1: population distribution of CYP2E1 activity," Journal of Toxicology and Environmental Health-Part B, vol. 12, no. 5-6, pp. 362388,2009 . 

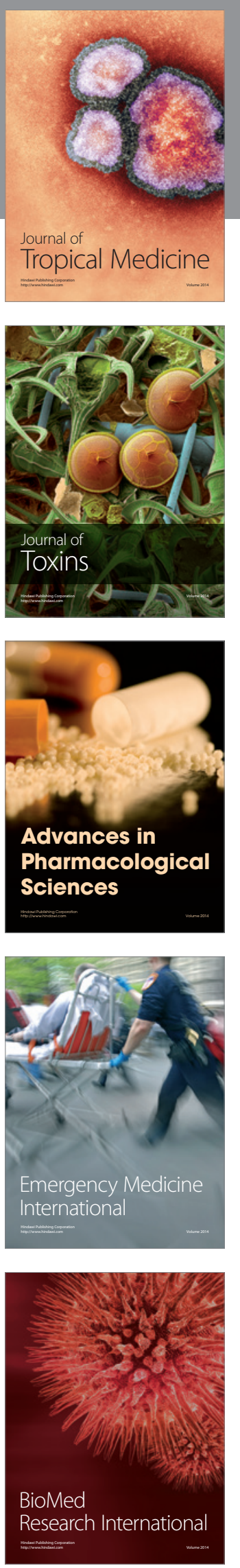
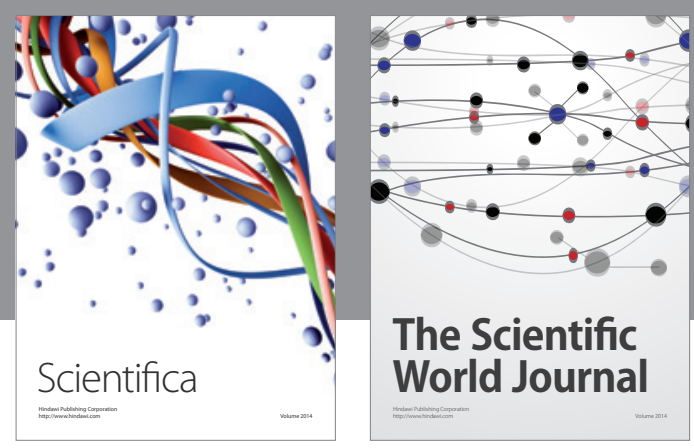

The Scientific World Journal
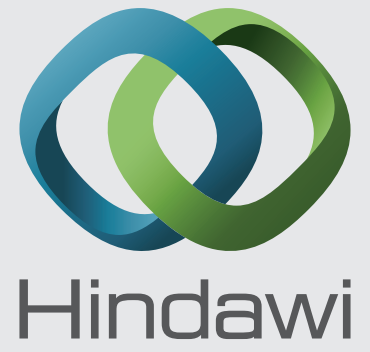

Submit your manuscripts at

http://www.hindawi.com
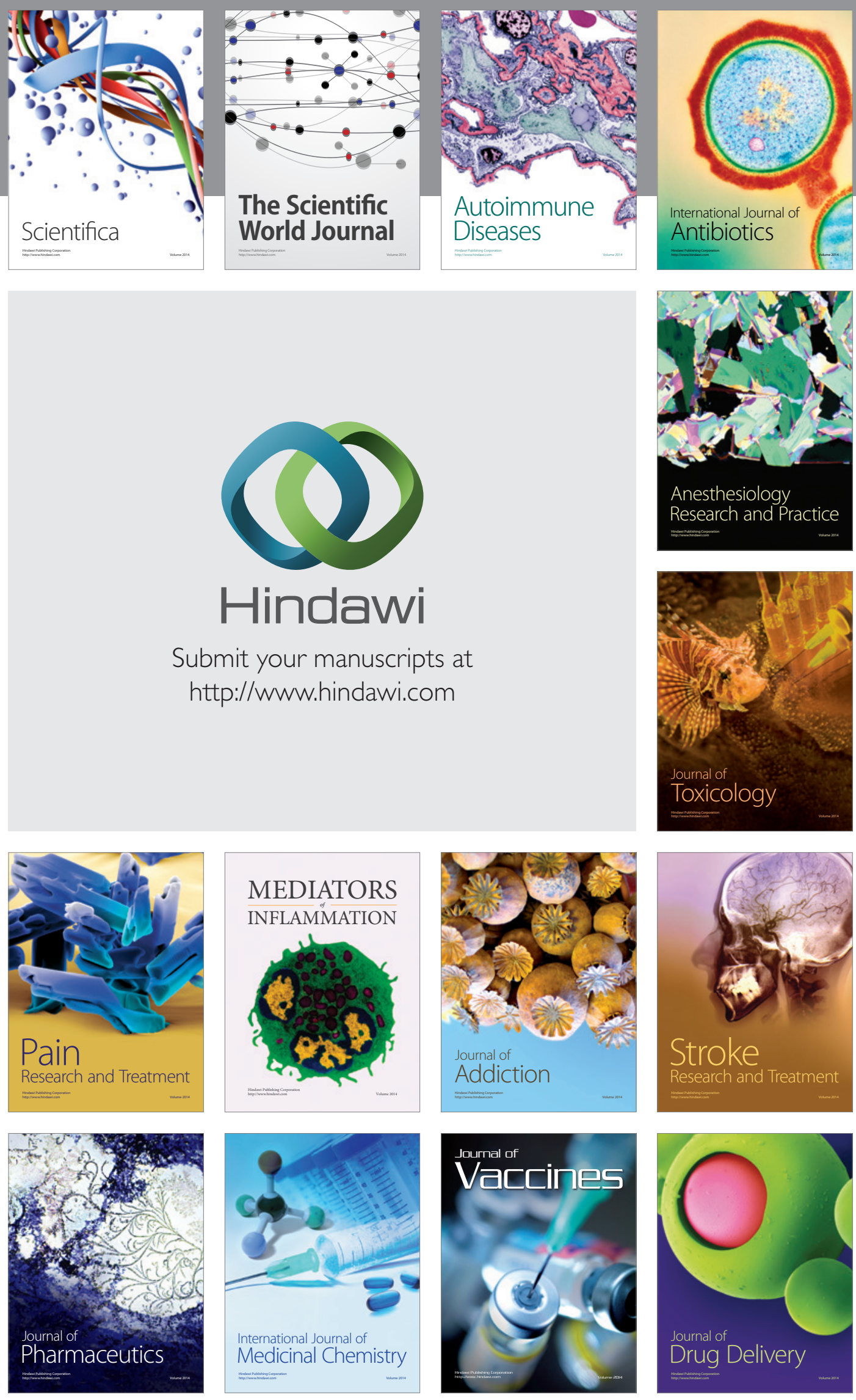